\title{
Temporal and Spatial Microalgae Diversity in Lake Bishoftu- Guda/ Babugaya, Ethiopia
}

\section{Nega R*, Etisa D and Lule W \\ Microbial Biodiversity Directorate, Ethiopian Biodiversity Institute, Ethiopia}

*Corresponding author: Roman Nega, Microbial Biodiversity Directorate, Ethiopian Biodiversity Institute, Addis Ababa, Ethiopia, Tel: 251-918169601; Email: romannega32@gmail.com

\section{Research Article \\ Volume 4 Issue 1}

Received Date: December 18, 2019

Published Date: January 07, 2020

DOI: $10.23880 /$ jenr-16000184

\section{Abstract}

Spatio-temporal variations in microalgae distribution are widely affected by water physico- chemical factors such as To, salinity, $\mathrm{pH}$, nitrate, nitrite, ammonia, silicate and IP. The effect of these factors on microalgae community changes species composition and their diversity in the fresh water ecosystem. Stratified random sampling design was conducted in Lake Babogaya of Ethiopia from 2017- 2018 to assess the spatial and temporal diversity of microalgae. 120 samples were collected in dry season (February to march), flowering season (September to November), wet season and (July to August) from Lake Babogaya. Water samples were collected seasonally from selected sites using sterile glass bottles starting from site one in offshore by considering depth and representativeness of the sample for the sites. Water temperature and $\mathrm{pH}$ and water transparency (SD) was determined. Lake Babogaya had the average water temperature $18.75^{\circ} \mathrm{C}$ during wet season, $26.6^{\circ} \mathrm{C}$ during flowering season, $23.55^{\circ} \mathrm{C}$ during dry season and SD of the lake ranged from $35 \mathrm{~cm}$ (flowering season) to $194 \mathrm{~cm}$ (dry season. High pH values were recorded in dry season (9.1) followed by flowering season (9.0) and then wet season (8.5) in Lake Babogaya. All sites in Lake Babogaya have consistency values of pH in all three season. A total of 52 microalgae genera/ species belonging to 7 phyla were identified at the eight sites during the three seasons (wet, flowering and dry) (Table 3). Chlorophyta was the most dominant phylum in all three seasons with 28 species representing $53.84 \%$ followed by Cyanophyta (10 species, 19.23\%) and Bacillariophyta (7 species, 13.46\%). In the present study microalgae species number is high in wet season $(n=39)$ this may be due to clarity of water (low turbidity) that transmit the light and the suitable temperature. Cloth washing, bathing and grazing site was the richest in terms of species diversity with 43 microalgae genera and followed by Adulala resort with 41 microalgae genera and youth center was the least diversed site with 22 microalgae genera. In the present study the most dominant species and the relative abundance of species in each seasons were Chrococcus (wet season) ( $\mathrm{Y}=75.5, \mathrm{RA}=18.4$ ), Oocystis lacustis (flowering season) ( $\mathrm{Y}=123.48, \mathrm{RA}=34.78)$ and Chlamydomonas species (dry season) ( $\mathrm{Y}=74, \mathrm{RA}=28.57)$. All the eight sites had almost same types of microalgae species. The Shannon equitability values were $0.7,0.67$ and 0.7 for wet, flowering and dry seasons respectively. The Shannon diversity indices were 3.26, 2.91 and 3.04 during wet, flowering and dry seasons 
respectively. In all three seasons high diversity index was showed during wet season and lower diversity was showed in flowering season. Significance difference were recorded between seasons and among sampling sites and correlation between seasons are significant at $\mathrm{p}<0.05$.

Keywords: Microalgae; Spatial; Temporal; Bishoftu-Guda; Diversity

\section{Introduction}

Rich natural resources that occur within the environment are characterized by having greater biodiversity [1-3]. Microalgae are the major primary producers in many aquatic systems and are an important food for consumers. They are photosynthesizing microscopic organisms that inhabit the upper sunlit layer of almost all oceans and bodies of freshwater. They are agents for primary production, the creation of organic compounds from carbon dioxide dissolved in the water a process that sustain the aquatic food web [4]. They are responsible for much of photosynthetic activity on the Earth and hence responsible for the oxygen presents in the Earth's atmosphere [5,6]. They are one of the major biological components of aquatic ecosystems, play important roles in water bodies, not only as primary producers and hence as the base of food chains, but also as one of the dependable indicators of lake fertility and environmental changes.

The diversity of a microalgae community can be used to characterize its structure (number of species present, their physiological properties and by the genetic potential of the organisms making up the community) [7]. Understanding the chemical and physical factors controlling population dynamics of phytoplankton is essential for the understanding of how human activities affect water quality of freshwater ecosystems $[8,9]$. The seasonal fluctuations in phytoplankton abundance and species composition in any water body is due to differential response of different species to changing levels of light, temperature, nutrients, grazing pressure, onset of parasitic infection, extracellular metabolites of plants and animals with a change in season during a course of year [10]. According to Reynold [11], seasonal changes in a natural phytoplankton community are best interpreted as alterations between true succession and intermediate disturbances (such as floods, episodes of increased wind mixing or they are biotic, including factors like grazing). Therefore, it may be expected that structurally stable lakes follow rather gradual seasonal changes. However, such seasonal changes may be overridden in lakes subject to intermediate disturbances.
As there is some indication that temporally variable disturbances increase diversity [12,13]. Spatial and temporal variations in microalgae distribution are widely affected by the water chemical and physical factors such as temperature, salinity, $\mathrm{pH}$, nitrate, nitrite, ammonia, silicate and IP. The influence of these factors on microalgae community changes species composition and their diversity in the fresh water ecosystem [14].

Compared to many other countries in the world, Ethiopia is gifted with a large number of standing water bodies, whose sustainable use can contribute to the economy of the country. The lakes are critical to the survival of local communities as they are the actual and potential sources of food and income. Furthermore, their range of variations in morphometry, physical and chemical features offers opportunities for superb comparative limnological studies. Some studies have been done regarding the Phytoplankton composition, biomass and primary productivity of Ethiopian rift valley lakes $[15,16]$. According to Zinabu Gebremariam [17], the close proximity of urbanization and human settlement to Ethiopian lakes is among the greatest potential causes of changes in water quality.

Lake Babogaya surrounded by a fast growing town, Bishoftu and its shores are used for washing clothes, watering livestock and recreation and the like. The growing population and the agricultural practices around the lake have serious impacts on the lakes. It is possible for the wastes from these sources to find their way to the lake and cause eutrophication and also could lead to changes in the physico-chemical limnological features of the lake resulting in the disruption of the lake ecosystem, with consequent changes in the species composition and photosynthetic production of phytoplankton. And also Shoreline modifications made on almost all sides of the lake for various purposes (e.g. for the construction of resort hotels and residences in the catchments) introduce enormous amounts of particulate wastes, which form suspensions in the water column thereby reducing light penetration at least in the near-shore regions of the lakes. These activities could lead to changes in the physicochemical limnological features of the lake resulting in the 
disruption of the lake ecosystem, with consequent changes in the species composition and photosynthetic production of phytoplankton. It is also possible that degradation of this aquatic ecosystem may go on unnoticed for a long time and eventually result in unexpected disastrous effects. The lake is critical to the survival of local communities as they are the actual and potential sources of food and income.

Despite their importance, the limnology of the two Ethiopian lakes is unexplored/ has not received attention in spite of its potential economic importance. So, the purpose of this research study was, therefore to study the temporal and spatial microalgae dynamics in Lake Babogaya.

\section{Materials and Methods}

\section{Description of the Study Area}

Lake Babogaya is one of the crater lakes located $47 \mathrm{~km}$ southeast of Addis Ababa in Bishoftu town, within the main Ethiopia rift valley lake. Lake Babogaya found at an altitude of 1869. Like the other volcanic crater lakes of the area, Lake Babogaya is a closed system surrounded by very steep and rocky hills. The vertical distance from the lake's surface to the crater rim is $20 \mathrm{~m}$, and this affords moderate protection from wind [18].

\section{Study design and Sample size}

Stratified random sampling design was conducted in Lake Babogaya of Ethiopia from 2017- 2018 to assess the spatial and temporal diversity of microalgae. 120 samples were collected in dry season (February to march), flowering season (September to November), wet season and (July to August= less rain during sampling) from Lake Babogaya. The sampling stations for Lake Babugaya were selected based on high human and animal intervention sites (near-shore station), Recreational sites/resorts and free intervention sites. Physical parameter data like $\mathrm{pH}$ (pHep pocket size $\mathrm{pH}$ meter, HANNA), temperature and Secchi depth were the most important steps for proper sampling. GPS (AndroiTS GPS Test Pro) was used to define the sites.

\section{Sampling collection and laboratory analysis}

Samples of water were collected seasonally from selected sites (Table 1) using sterile glass bottles starting from site one in offshore by considering depth and representativeness of the sample for the sites. Water temperature and $\mathrm{pH}$ readings were obtained in the field at each sampling site using a portable multi-probe (pHep pocket size $\mathrm{pH}$ meter, HANNA) while water transparency (SD) was determined using Secchi disk. The fresh water sample was fixed with $1 \mathrm{ml}$ of $4 \%$ of formaldehyde solution (purchased from a local pharmacy). Then the mixture was allowed to settle for $24 \mathrm{~h}$. Then, water samples were transported to the laboratory for identification of microalgal genera/ species. Preserved water samples were examined using inverted microscope (WILD M 40), at a magnification of $x 40$. Genera/ species identification was done by placing six drops of water on a glass slide until no more new microalgae species found. The identification to genus or species level was made on the basis of various descriptors of microalgae $[19,20]$.

\begin{tabular}{|c|c|}
\hline Sites for lake Babugaya & Sample Collection sites \\
\hline Site 1 & Bahir hayl \\
\hline Site 2 & Lisak resort \\
\hline Site 3 & Adulala resort \\
\hline Site 4 & Babugaya resort \\
\hline Site 5 & Youth center \\
\hline Site 6 & ILRI (free intervention) \\
\hline Site 7 & Center (free intervention) \\
\hline Site 8 & $\begin{array}{c}\text { Cloth washing, bathing and } \\
\text { grazing }\end{array}$ \\
\hline
\end{tabular}

Table 1: sample collection sites of Lake Babugaya, Bishoftu.

\section{Data Analysis}

Spatial and temporal variation in the composition of microalgae species was assessed by analysis of variance (ANOVA) using SPSS 20. Differences were considered significant at $\mathrm{p}<0.05$ (95\%) confidence level. The abundance of the species were got by counting microalgae species observed using microscope (frequency of each species). Microalgal dominance species and relative abundance were analyzed by calculating diversity indices (DI)

\section{Shannon Diversity Index (H)}

The Shannon diversity index was calculated by following Odum [21].

Diversity Index $(\mathrm{H})=-\Sigma \mathrm{Pi} \ln \mathrm{Pi}$, Where Pi $=\mathrm{S} / \mathrm{N}$

$\mathrm{S}=$ Number of individuals of one species

$\mathrm{N}=$ Total number of all individuals in the sample

In = Logarithm to base e

Similarly the Evenness Index $\left(\mathrm{E}_{\mathrm{H}}\right)$ was calculated by following Pielou [22].

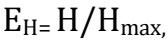

Where $\mathrm{H}$ max is the maximum value of diversity: Hmax= $(\ln S)$

Dominant species were determined using Equation (Lampitt, et al. [23]) 
$\mathrm{Y}=(\mathrm{ni} / \mathrm{N}) \mathrm{fi}$

Where ni= denotes the number of algae of species $i$

$\mathrm{N}=$ the total number of algae in the sample

$\mathrm{fi}=$ denotes the frequency of the species $\mathrm{i}$ appearing in the sample

$\mathrm{Y}>0.02$ indicates dominant species.

\section{Relative abundance}

$\mathrm{RA}=$ total no of individual of species/total no of individual of all species recorded*100

\section{Results and Discussion}

\section{Seasonal and temporal variation of $\mathrm{pH}$, temperature and transparency (SD)}

The seasonal and temporal values of $\mathrm{pH}$, temperature and transparency (SD) recorded among the sampling sites within the study period are presented in Tables 2 and 3. Lake Babogaya had the average water temperature $18.75^{\circ} \mathrm{C}$ during wet season, $26.6^{\circ} \mathrm{C}$ during flowering season, $23.55^{\circ} \mathrm{C}$ during dry season and SD of the lake ranged from $35 \mathrm{~cm}$ (flowering season) to $194 \mathrm{~cm}$ (dry season. This finding was consistent with the finding of Brook Lemma (2009) the SD transparency was (140-160 $\mathrm{cm}$ ) in L. Bishoftu-Guda and L. Hora-Arsedi (47-68 cm). High pH values were recorded in dry season (9.1) followed by flowering season (9.0) and then wet season (8.5) in Lake Babogaya. All sites in Lake Babogaya have consistency values of $\mathrm{pH}$ in all three season. The $\mathrm{pH}$ values of Lake Babogaya are comparable to those of Lake Bishoftu (9.20; Zinabu [17]) and the Rift Valley Lake Chamo (8.53 to 9.44; Eyasu [24]). The pH values of Lake Babogaya was different from Lake Arenguade in Ethiopia (Talling, et al. [25]), which has $\mathrm{pH}$ values between 9.510.50 that tend to remain at high levels owing to the high buffering capacity of the lake waters [25]. A PH range of 6.5 to 8.5 is acceptable for aquatic biota according to the APHA [26]. Although the present Secchi depth readings of the lake are much lower than those reported for the same lake, for Lake Babogaya (1.48 to $4.46 \mathrm{~m}$; Yeshiemebet Major [27]). The maximum water temperatures of Lake Babogaya are closer to Lake Hawassa $\left(23.8\right.$ to $\left.28.4^{\circ} \mathrm{C}\right)$ [15]) and Lake Chamo $\left(26-30^{\circ} \mathrm{C}\right)[28]$.

\begin{tabular}{|c|c|c|c|c|}
\hline Sampling site & season & temperature & pH & SD( transparency) \\
\hline 1 & 1 & 18.00 & 8.7 & 71 \\
\hline 1 & 2 & 23.20 & 9.0 & 67 \\
\hline 1 & 3 & 20.00 & 9.1 & 71 \\
\hline 2 & 1 & 19.50 & 8.7 & 76 \\
\hline 2 & 2 & 23.20 & 9.0 & 40 \\
\hline 2 & 3 & 21.10 & 9.1 & 67 \\
\hline 3 & 1 & 18.50 & 8.6 & 65 \\
\hline 3 & 2 & 24.30 & 9.0 & 40 \\
\hline 4 & 3 & 24.70 & 9.1 & 57 \\
\hline 4 & 1 & 18.50 & 8.6 & 42 \\
\hline 4 & 2 & 24.00 & 9.0 & 194 \\
\hline 5 & 3 & 24.70 & 9.1 & 68 \\
\hline 5 & 1 & 18.50 & 8.6 & 183 \\
\hline 5 & 2 & 23.70 & 9.0 & 43 \\
\hline 6 & 3 & 25.30 & 9.1 & 65 \\
\hline 6 & 1 & 18.50 & 8.5 & 35 \\
\hline 6 & 2 & 23.40 & 9.0 & 150 \\
\hline 7 & 3 & 26.00 & 9.1 & 67 \\
\hline 7 & 1 & 18.50 & 8.5 & 153 \\
\hline 7 & 2 & 26.70 & 9.0 & 42 \\
\hline 8 & 3 & 23.80 & 9.1 & 65 \\
\hline 8 & 1 & 19.00 & 8.5 & 147 \\
\hline 8 & 2 & 30.00 & 9.0 & 45 \\
\hline
\end{tabular}

Note: sampling sites (from 1-8), season (1=wet, $2=$ flowering, $3=$ dry).

Table 2: Water $\mathrm{pH}$, water temperature and water transparency (SD) in the temporal (wet, flowering and dry) and spatial dimension (from site 1-8) from the selected sampling sites inside lake Babugaya. 


\section{Spatial and temporal distribution of Microalgae}

A total of 52 microalgae genera/ species belonging to 7 phyla were identified at the eight sites during the three seasons (wet, flowering and dry) (Table 3). Chlorophyta was the most dominant phylum in all three seasons with 28 species representing $53.84 \%$ followed by Cyanophyta (10 species, 19.23\%) and Bacillariophyta (7 species, $13.46 \%$ ). This is inconsistent with the findings of Yeshiemebet [27] indicated the dominance of Dinoflagellates and Bacillariophyta (diatoms) and Wood and Tailing [29] finding showed that the dominance of blue-green algae, particularly of Microcystis aeruginosa in Lake Bishoftu-Guda. According to Shariff [30] Chlorophyta have the ability to live in wide range of nutrients and physical environments. They are considered opportunistic for their small size and rapid growth, favoring its presence in any season of the year [31].

In the present study microalgae species number is high in wet season $(n=39)$ this may be due to clarity of water (low turbidity) that transmit the light and the suitable temperature. A study by Hofmann [32] in lake showed that phytoplanktons were greatly reduced in numbers and abundance following heavy precipitation. Cloth washing, bathing and grazing site was the richest in terms of species diversity with 43 microalgae genera and followed by Adulala resort with 41 microalgae genera and youth center was the least diversed site with 22 microalgae genera. These two sites had flood inflows and a lot of anthropogenic activities like washing clothes, bathing and grazing of animals. Due to these detergents, animal and human wastes wash in to the water. This may increase availability of nutrients from human and animal wastes, cloth washing (using detergents) and fertilizer that wash into water. That would be the reason these sites were dominated by cyanophytes taxa mostly in wet seasons when there was rain and flood. According to Congressional Report HR, [33] the principal source of effluent phosphorus was from phosphates used in laundry detergents. Overloading of phosphorus is usually considered as the primary causation, which leads to significant shifts in phytoplankton species composition towards bloom-forming cyanobacterial domination [34].
Youth center, Bahir hayl and Cloth washing, bathing and grazing (intervention) sites were dominated by Chlorophyta in flowering and dry seasons. Sites like Center (free intervention), ILRI, Lisak resort, Babogaya resort and Adulala resort were dominated by Cyanophyta in wet season but Cyanophyta and Chlorophyta were variably dominant in flowering and dry season (Figures 15). In the present study the most dominant species and the relative abundance of species in each seasons were Chrococcus (wet season) (Y=75.5, RA=18.4), Oocystis lacustis (flowering season) $(\mathrm{Y}=123.48, \mathrm{RA}=34.78)$ and Chlamydomonas species (dry season) $(\mathrm{Y}=74, \mathrm{RA}=28.57)$ (Table 4).

All the eight sites had almost same types of microalgae species. The Shannon equitability values were $0.7,0.67$ and 0.7 for wet, flowering and dry seasons respectively. The highest numbers of species (19 and 14) were recorded during wet and flowering season respectively at the site of human and animal intervention and in dry season the highest numbers of species were recorded at the site of ILRI (16). The least microalgae species number were recorded at the sites of youth center during dry season. Furthermore, regardless of the study site, the dominant phyla were Chlorophyta, which had more number of species that occurred throughout the year. The Shannon diversity indices were 3.26, 2.91 and 3.04 during wet, flowering and dry seasons respectively. In all three seasons high diversity index was showed during wet season and lower diversity was showed in flowering season. In accordance with Cavalcanti and Larrazábal [35], the Shannon diversity can be assessed as very low values lower than 1.0, low (between 2.0 and 1.0), medium (between 3.0 and 2.0) and high (above 3.0). According to these criteria, the diversity of the microalgae community recorded during wet and dry season can be classified as high and flowering season was classified as medium. Several studies have shown that a high diversity index indicates that the ecosystem is in a healthy and stable state, while a low value suggests a less healthy or degraded ecosystem [36]. Significance difference were recorded between seasons and among sampling sites and correlation between seasons are significant at $\mathrm{p}<0.05$.

\begin{tabular}{|c|c|c|c|c|}
\hline \multirow{3}{*}{ phylum } & \multirow{2}{*}{ Identified species/genera } & \multicolumn{3}{|c|}{ Study periods } \\
\cline { 2 - 5 } & Oocystis spp. & $\mathrm{J}$ & October-November & March- April \\
\hline \multirow{5}{*}{ Chlorophyta } & Chlamydomonas & $\mathrm{x}$ & - & $\mathrm{x}$ \\
\cline { 2 - 5 } & Cosmarium depressum & $\mathrm{x}$ & - & $\mathrm{x}$ \\
\cline { 2 - 5 } & Tetraedron minimum & $\mathrm{x}$ & $\mathrm{x}$ & $\mathrm{x}$ \\
\cline { 2 - 5 } & Peridinium cinctum & $\mathrm{x}$ & - & - \\
\cline { 2 - 5 } & Selenastrum bibraianum & $\mathrm{x}$ & $\mathrm{x}$ & $\mathrm{x}$ \\
\hline
\end{tabular}




\section{Journal of Ecology \& Natural Resources}

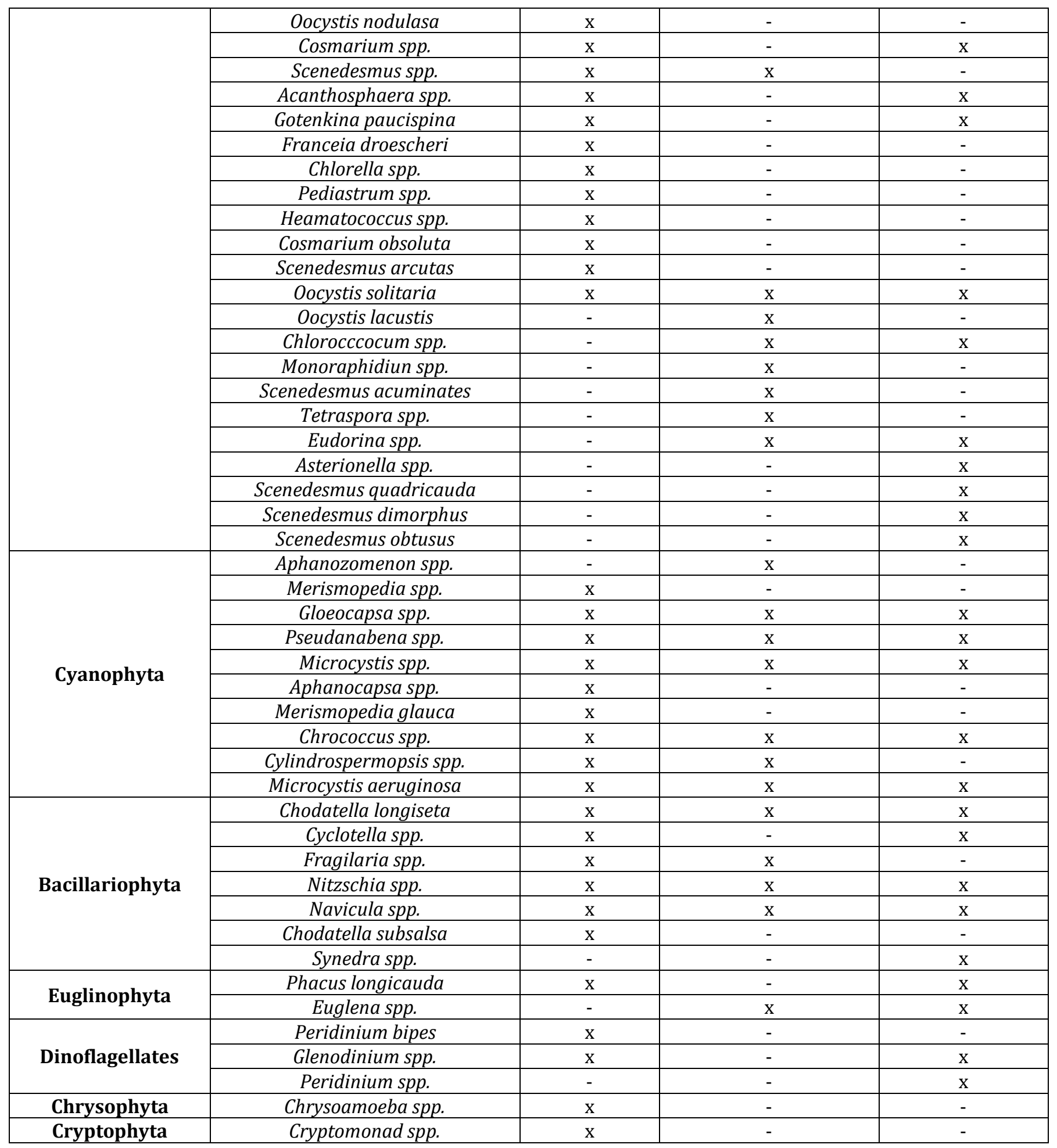

Note:- $\mathrm{X}=$ microalgae presents in three season, -= absence of microalgae in three seasons.

Table 3: Microscopically identified microalgae genera/ species from eight sites during three seasons, Lake Babugaya. 


\section{Journal of Ecology \& Natural Resources}

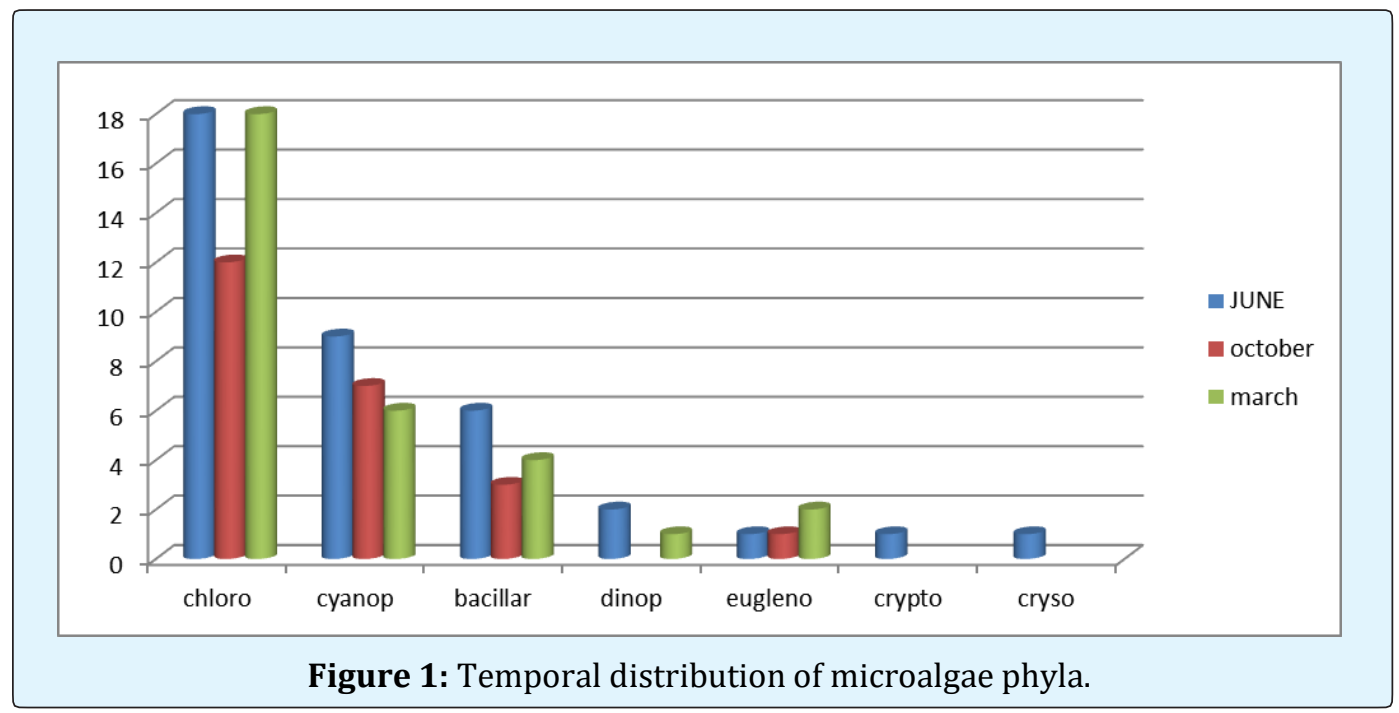

\begin{tabular}{|c|c|c|c|c|}
\hline Wet season microalgae species & phyla & fi/frequency & Y(dominant) & RA(relative abundance) \\
\hline Oocystis spp & Chlorophyta & 53 & 5.579 & 10.526 \\
\hline Chlamydomonas & Chlorophyta & 263 & 55.37 & 21.053 \\
\hline Cosmarium depressum & Chlorophyta & 66 & 3.474 & 5.2632 \\
\hline Tetradron minimum & Chlorophyta & 314 & 66.11 & 21.053 \\
\hline Merismopedia & Cyanophyta & 63 & 11.61 & 18.421 \\
\hline Peridinium cinctum & Chlorophyta & 36 & 0.947 & 2.6316 \\
\hline Gloeocapsa & Cyanophyta & 169 & 31.13 & 18.421 \\
\hline Pseudanabena & Cyanophyta & 27 & 4.974 & 18.421 \\
\hline Chodatella longiseta & Bacillariophyta & 22 & 1.158 & 5.2632 \\
\hline Microcystis Spp & Cyanophyta & 40 & 6.316 & 15.789 \\
\hline Selenastrum bibraianum & Chlorophyta & 148 & 3.895 & 2.6316 \\
\hline Aphanocapsa & Cyanophyta & 5 & 0.263 & 5.2632 \\
\hline Oocystis nodulasa & Chlorophyta & 29 & 0.763 & 2.6316 \\
\hline Cosmarium & Chlorophyta & 157 & 33.05 & 21.053 \\
\hline Merismopedia glauca & Cyanophyta & 12 & 0.632 & 5.2632 \\
\hline Scenedesmus & Chlorophyta & 13 & 0.342 & 2.6316 \\
\hline Acanthosphaera & Chlorophyta & 1 & 0.026 & 2.6316 \\
\hline Gotenkina paucispina & Chlorophyta & 3 & 0.079 & 2.6316 \\
\hline Peridinium bipes & Dinoflagellate & 4 & 0.105 & 2.6316 \\
\hline Chrococcus & Cyanophyta & 410 & 75.53 & 18.421 \\
\hline Glenodinium & Dinoflagellate & 5 & 0.132 & 2.6316 \\
\hline Chrysoamoeba & Chrysophyta & 2 & 0.053 & 2.6316 \\
\hline Cylindrospermopsis & Cyanophyta & 16 & 2.105 & 13.158 \\
\hline Franceia droescheri & Chlorophyta & 1 & 0.026 & 2.6316 \\
\hline Microcystis aeruginosa & Cyanophyta & 7 & 0.553 & 7.8947 \\
\hline Cyclotella & Bacillariophyta & 8 & 1.263 & 15.789 \\
\hline Fragilaria & Bacillariophyta & 5 & 0.132 & 2.6316 \\
\hline Nitzschia & Bacillariophyta & 1 & 0.026 & 2.6316 \\
\hline Chlorella & Chlorophyta & 1 & 0.026 & 2.6316 \\
\hline Pediastrum & Chlorophyta & 1 & 0.026 & 2.6316 \\
\hline Heamatococcus & Chlorophyta & 1 & 0.026 & 2.6316 \\
\hline Cryptomonad & Cryptophyta & 1 & 0.026 & 2.6316 \\
\hline Navicula & Bacillariophyta & 1 & 0.026 & 2.6316 \\
\hline
\end{tabular}




\begin{tabular}{|c|c|c|c|c|}
\hline Phacus longicauda & Euglinophyta & 4 & 0.105 & 2.6316 \\
\hline Cosmarium obsoluta & Chlorophyta & 10 & 0.263 & 2.6316 \\
\hline Chodatella subsalsa & Bacillariophyta & 1 & 0.026 & 2.6316 \\
\hline Scenedesmus arcutas & Chlorophyta & 3 & 0.079 & 2.6316 \\
\hline Oocystis solitaria & Chlorophyta & 13 & 0.342 & 2.6316 \\
\hline
\end{tabular}

\begin{tabular}{|c|c|c|c|c|}
\hline Flowering season microalgae species & phyla & fi/frequency & Y(dominant) & RA(Relative abundance) \\
\hline Tetraedron minimum & Chlorophyta & 57 & 17.348 & 30.43478 \\
\hline Oocystis solitaria & Chlorophyta & 168 & 58.435 & 34.78261 \\
\hline Oocystis lacustis & Chlorophyta & 355 & 123.48 & 34.78261 \\
\hline Chodatella & Chlorophyta & 16 & 2.7826 & 17.3913 \\
\hline Chloroccocum & Chlorophyta & 5 & 0.4348 & 8.695652 \\
\hline Selenastrum & Chlorophyta & 1 & 0.0435 & 4.347826 \\
\hline Monoraphidiun & Chlorophyta & 6 & 0.5217 & 8.695652 \\
\hline Scenedesmus & Chlorophyta & 6 & 0.5217 & 8.695652 \\
\hline Scenedesmus acuminatus & Chlorophyta & 5 & 0.4348 & 8.695652 \\
\hline Tetraspora & Chlorophyta & 3 & 0.2609 & 8.695652 \\
\hline Chlamydomonas & Chlorophyta & 5 & 0.4348 & 8.695652 \\
\hline Eudorina & Chlorophyta & 3 & 0.2609 & 8.695652 \\
\hline Gloeocapsa & Cyanophyta & 39 & 8.4783 & 21.73913 \\
\hline Microcystis Spp. & Cyanophyta & 166 & 50.522 & 30.43478 \\
\hline Microcystis aeruginosa & Cyanophyta & 14 & 3.0435 & 21.73913 \\
\hline Chrococcus minutus & Cyanophyta & 1 & 0.0435 & 4.347826 \\
\hline Aphanozomenon & Cyanophyta & 14 & 3.0435 & 21.73913 \\
\hline Cylindrospermopsis & Cyanophyta & 2 & 0.087 & 4.347826 \\
\hline Pseudanabena & Cyanophyta & 1 & 0.0435 & 4.347826 \\
\hline Nitzschia & Bacillariophyta & 1 & 0.0435 & 4.347826 \\
\hline Fragilaria & Bacillariophyta & 3 & 0.2609 & 8.695652 \\
\hline Navicula & Bacillariophyta & 7 & 0.913 & 13.04348 \\
\hline Euglena & Euglinophyta & 12 & 2.087 & 17.3913 \\
\hline & & & \\
\hline
\end{tabular}

\begin{tabular}{|c|c|c|c|c|}
\hline Dry season microalgae species & Phyla & fi & Y(dominance) & RA \\
\hline Selenastrum & Chlorophyta & 199 & 56.9 & 28.57 \\
\hline Chlamydomonas & Chlorophyta & 259 & 74 & 28.57 \\
\hline Eudorina & Chlorophyta & 9 & 0.32 & 3.571 \\
\hline Tetradron minimum & Chlorophyta & 26 & 1.86 & 7.143 \\
\hline Chloroccocum & Chlorophyta & 15 & 2.14 & 14.29 \\
\hline Gotenkina paucispina & Chlorophyta & 7 & 0.5 & 7.143 \\
\hline Oocystis & Chlorophyta & 2 & 0.14 & 7.143 \\
\hline Scenedesmus dimorphus & Chlorophyta & 11 & 0.79 & 7.143 \\
\hline Scenedesmus quadricauda & Chlorophyta & 3 & 0.11 & 3.571 \\
\hline Chodatella & Chlorophyta & 29 & 6.21 & 21.43 \\
\hline Cosmarium & Chlorophyta & 1 & 0.04 & 3.571 \\
\hline Acanthosphaera & Chlorophyta & 1 & 0.04 & 3.571 \\
\hline Scenedesmus obtusus & Chlorophyta & 1 & 0.04 & 3.571 \\
\hline Oocystis solitaria & Chlorophyta & 14 & 0.5 & 3.571 \\
\hline Asterionella & Chlorophyta & 2 & 0.14 & 7.143 \\
\hline Navicula & Bacillariophyta & 5 & 0.36 & 7.143 \\
\hline Cyclotella spp. & Bacillariophyta & 10 & 1.43 & 14.29 \\
\hline Synedra & Bacillariophyta & 15 & 1.07 & 7.143 \\
\hline
\end{tabular}




\section{Journal of Ecology \& Natural Resources}

\begin{tabular}{|c|c|c|c|c|}
\hline Nitzschia & Bacillariophyta & 11 & 0.79 & 7.143 \\
\hline Microcystis aeruginosa & Cyanophyta & 34 & 7.29 & 21.43 \\
\hline Pseudanabena & Cyanophyta & 12 & 0.86 & 7.143 \\
\hline Gloeocapsa & Cyanophyta & 142 & 10.1 & 7.143 \\
\hline Chrococcus & Cyanophyta & 9 & 0.32 & 3.571 \\
\hline Microcystis spp & Cyanophyta & 2 & 0.07 & 3.571 \\
\hline Euglena & Euglinophyta & 31 & 5.54 & 17.86 \\
\hline Phacus & Euglinophyta & 11 & 1.18 & 10.71 \\
\hline Peridinium & Dinoflagellates & 11 & 0.39 & 3.571 \\
\hline
\end{tabular}

Table 4: Dominant species and relative abundance of microalgae during three seasons in Lake Babugaya.
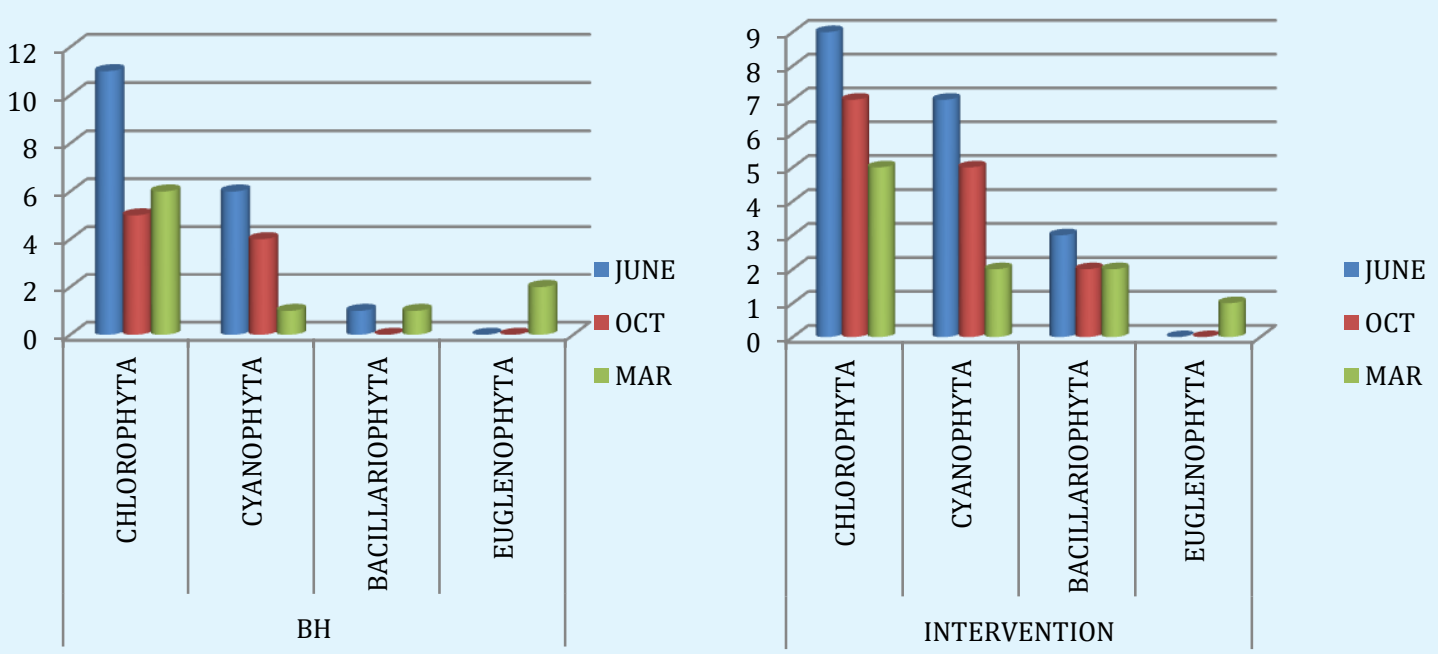

Figure 2: BH (Bahir Hayl) and clothing, microalgae phyla dynamics during June, October and March (three seasons wet, flowering and dry).
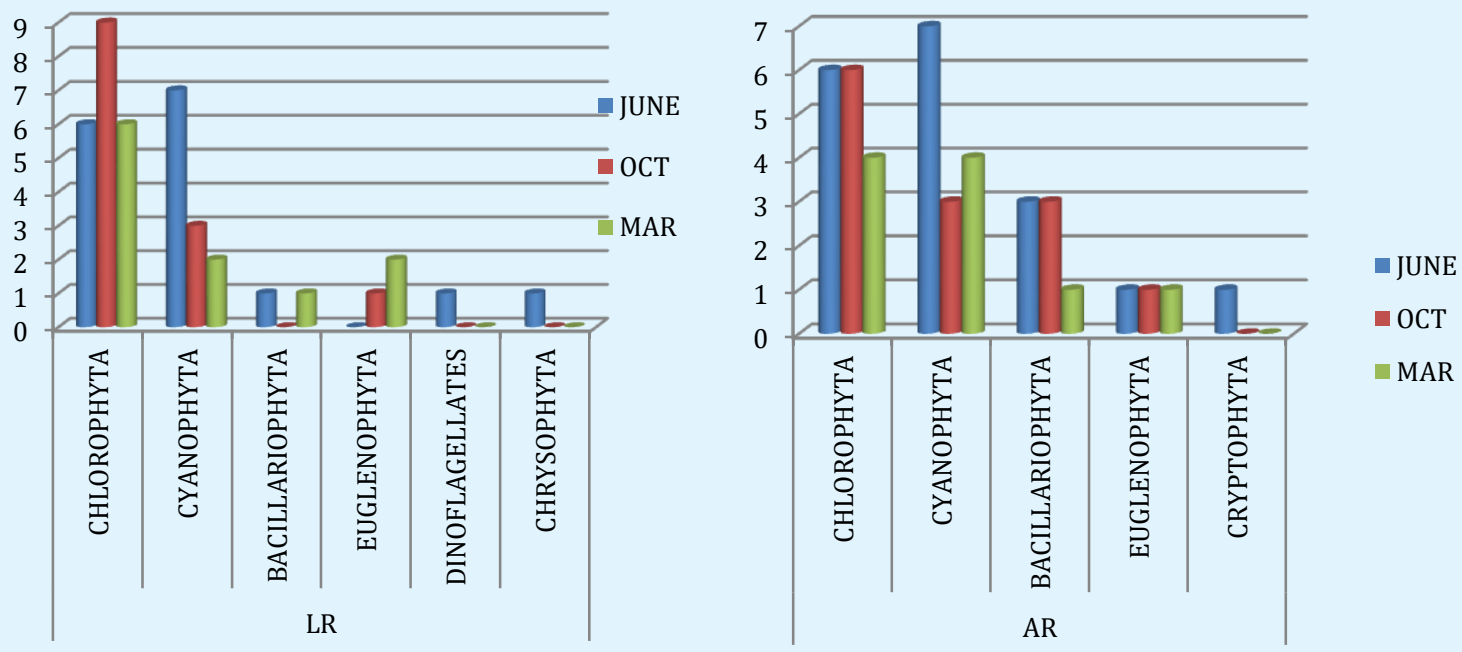

Figure 3: LR (Lisak Resort) and AR (Adulala resort) microalgae phyla dynamics during June, October and March (three seasons wet, flowering and dry). 

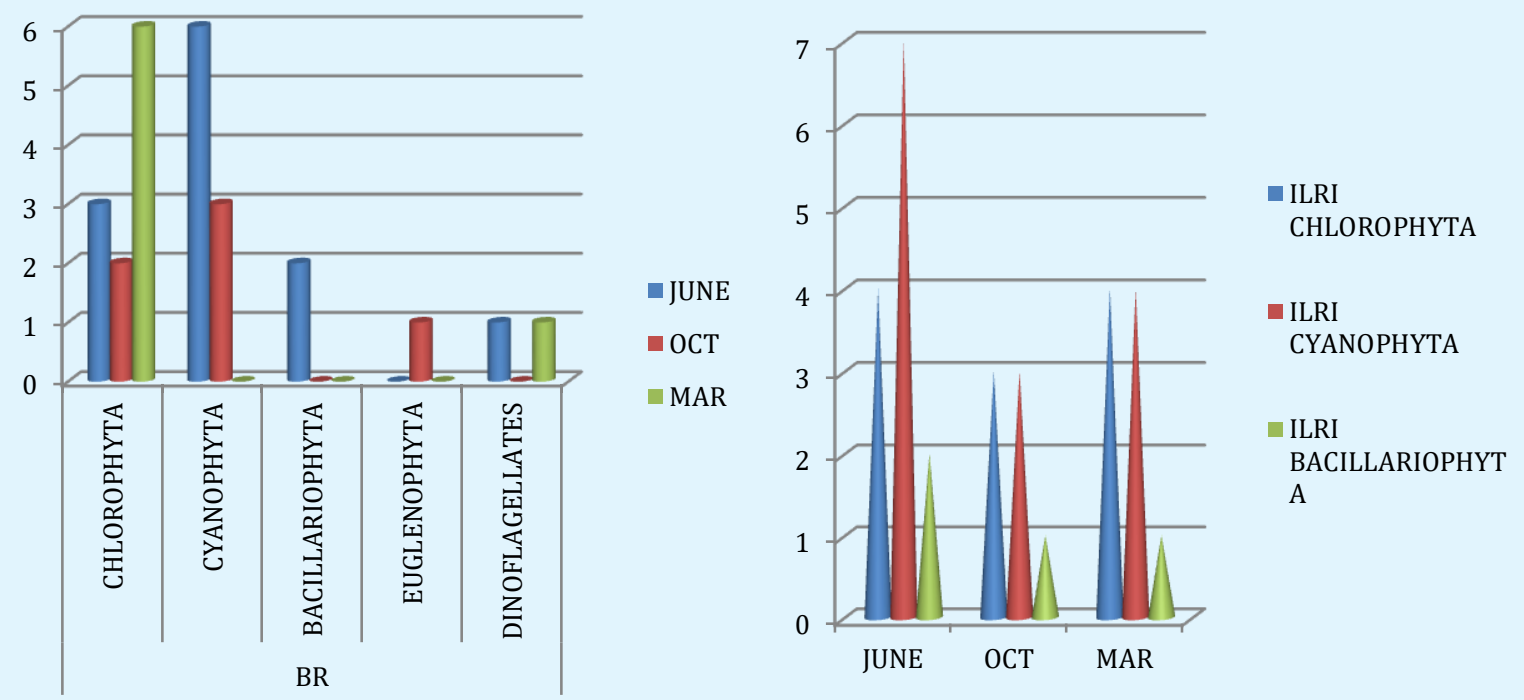

Figure 4: BR (Babugaya Resort) and ILRI (International Livestock Research Institute) microalgae phyla dynamics during June, October and March (three seasons wet, flowering and dry).
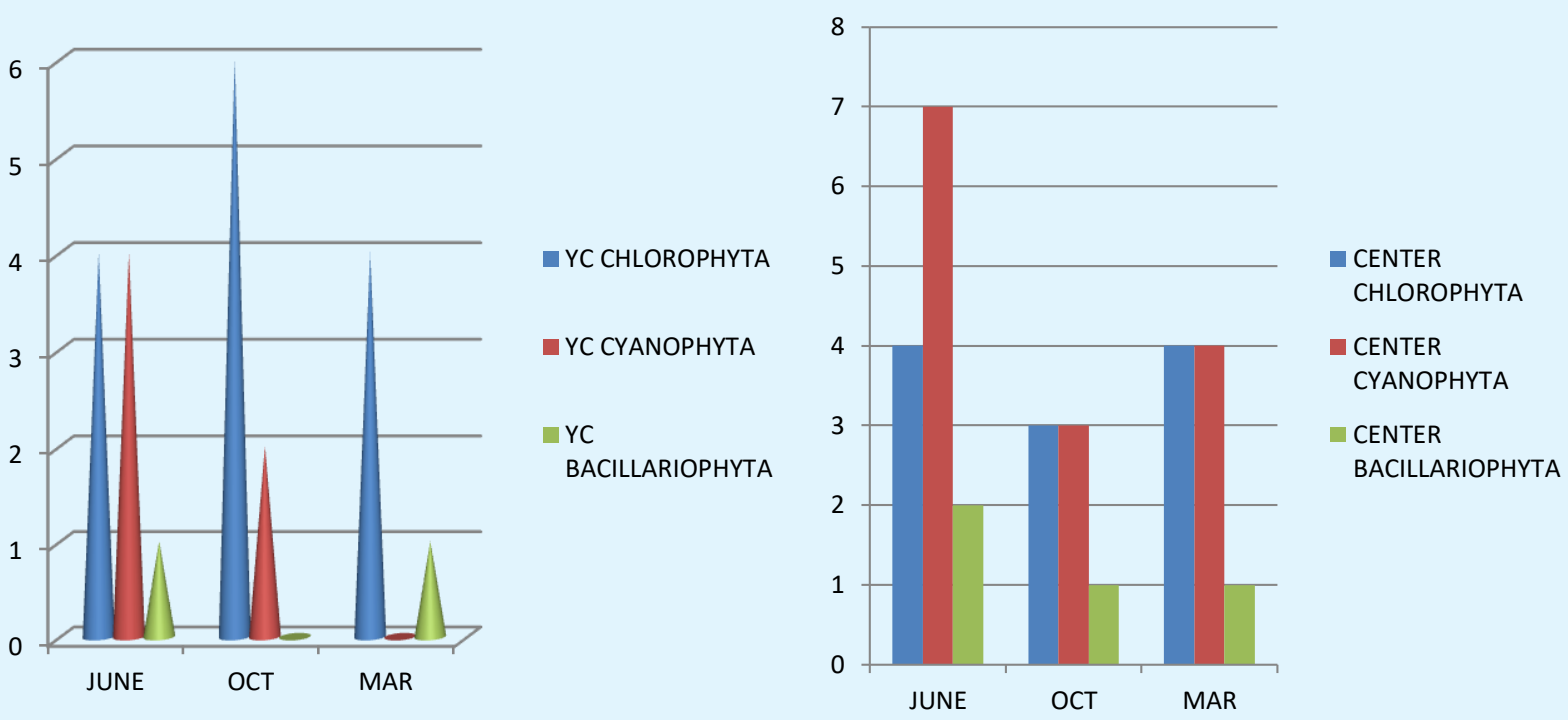

Figure 5: YC (Youth Center) and Center (free intervention) microalgae phyla dynamics during June, October and March (three seasons wet, flowering and dry).

\section{Conclusion and Recommendation}

\section{Conclusion}

In this study, Spatial and Temporal variation of microalgae, dominant species and relative abundance of the lake were observed. The dominant phyla were
Chlorophyta, which had more number of species that occurred throughout the year. Chlorophyta have the ability to live in wide range of nutrients and physical environments. They are considered opportunistic for their small size and rapid growth, favoring its presence in any season of the year. Microalgae species number is high in wet season, due to clarity of water (low turbidity) that 
transmit the light and the suitable temperature. Cloth washing, bathing and grazing site was the richest in terms of species diversity followed by Adulala resort. Youth center was the least diversed site. The highest numbers of species were recorded during wet and flowering season respectively at the site of human and animal intervention and in dry season the highest numbers of species were recorded at the site of ILRI. In all three seasons high diversity index was showed during wet season and lower diversity was showed in flowering season [37-39]. The Shannon diversity of the microalgae community recorded during wet and dry season can be classified as high and flowering season was classified as medium. Significance difference were recorded between seasons and among sampling sites and correlation between seasons are significant at $\mathrm{p}<0.05$.

\section{Recommendation}

Further studies are still needed on the species composition, quantity characteristics and distribution characteristics of the microalgae species in Bishoftu-Guda Lake for the upkeep of biodiversity. Water chemistry of the lake and phytoplankton community structure studies are still needed in order to find factors responsible for biodiversity loss. Freshwater ecosystems have been experiencing declines in biodiversity far greater than terrestrial ecosystems. If trends in human demands for water remain unaltered, species losses will surely continue at current rates. Microalgae can help in removing pollutants from the surroundings, restoring contaminated sites and preventing further pollution. Therefore, conservation and management of lakes ecosystems is critical to the interests of the entire mankind, as long as biodiversity constitutes a valuable natural resource in economic, cultural, aesthetic, scientific and educational terms.

\section{References}

1. Henderson HF, Ryder RA, Kudhogina AW (1973) Assessing fishery potentials of lakes and reservoirs. J Fish Board Cand 30(12): 2000-2009.

2. Oglesby RT (1977) Relationship of fish yield to Lake Phytoplankton standing crop, production and morphoedaphic factors. J Fish Res Board Cand 34(12): 2271-2279.

3. Melack JM (1976) Limnology and dynamics of phytoplankton in equatorial African lakes [Dissertation], Duke University, Durham, pp: 453.
4. Ghosal R, Wray SM (2011) The effects of turbulence on phytoplankton. Aerospace Technological Enterprise.

5. NASA (2009) Satellite detects red glow to map global ocean plant health.

6. NASA (2005) Satellite sees ocean plants increase, coasts greening.

7. Elber F, Schanz F (1989) The cause of change in the diversity and stability of phytoplankton community in small lakes. Freshwater boil 21(2): 137-251.

8. Reynolds CS (2006) The ecology of phytoplankton. Cambridge University Press, Cambridge, pp: 1-300.

9. Levinton JS (2013) Marine biology: function, biodiversity, ecology. Oxford University press, New York, pp: 173-193.

10. Adon M, Ouattara A, Gourene G (2011) Seasonal variation in the diversity and abundance of phytoplankton in a small African tropical reservoir. Afr J Microbiol Res 5(18): 2616-2626.

11. Reynolds CS (1988) The concept of ecological succession applied to seasonal periodicity of freshwater phytoplankton. Verh Int Ver Limnol 23(2): 683-691.

12. Gaedeke A, Sommer U (1986) The influence of the frequency of periodic disturbances. Oecologia 71(1): 98-102.

13. Padisák J, Tóth LG, Rajczy M (1988) The role of storms in the summer succession of the phytoplankton community in a shallow lake (Lake Balaton, Hungary). J Plankton Res 10(2): 249-265.

14. Madhu NV, Jyothibabu R, Balachandran KK, Honey UK, Martin GD, et al. (2007) Monsoonal impact on planktonic standing stock and abundance in a tropical estuary (Cochin Backwaters-India) Estuar. Coast Shelf Sci 73(1-2): 54-64.

15. Demeke Kifle (1985) Variation in phytoplankton primary production in relation to light and nutrients in Lake Awassa, MSc. Thesis, Addis Ababa University, pp: 108.

16. Girma Tilahun (1988) A Seasonal study on phytoplankton primary production in relation to light and nutrients in Lake Ziway. MSc. Thesis, Addis Ababa University pp: 62.

17. Zinabu GM (1994) Long-term changes in indices of chemical and productivity status of a group of tropical 
Ethiopian lakes, with differing exposure to human influence. Arch Hydrobiologia 132(1): 115-125.

18. Baxter RM (2002) Lake Morphometry and chemistry. Ethiopian Rift Valley lakes. In: Tudorancea C \& Taylor WD (eds.), Backh Publishers, Leiden, The Netherlands, pp: 45-60.

19. John D, Robert G (2002) Freshwater Algae of North America Ecology and Classification. A volume in Aquatic Ecology. ISBN: 978-0-12-741550-5.

20. Bellinger EG, Sigee DC (2010) 'Freshwater Algae: Identification and Use as Bioindicators.' (Wiley: Chichester, UK).

21. Odum E (1969) The strategy of ecosystem development. Science 164(3877): 262-270.

22. Pielou E (1967) The use of information theory in the study of the diversity of biological pollutions. Symp Math Stat Prob 4: 163-177.

23. Lampitt RS, Wishner KF, Turley CM, Angel MV (1993) Marine snow studies in the Northeast Atlantic Ocean: Distribution, composition and role as a food source for migrating plankton. Mar Biol 116: 689-702.

24. Eyasu S (2004) The temporal and spatial variations in the biomass and photosynthetic production of phytoplankton in relation to some physico- chemical variables in Lake Chamo Ethiopia. M.Sc. Thesis, Addis Ababa University, Addis Ababa pp: 72.

25. Talling J, Lemoalle J (1998). Ecological dynamics of tropical inland waters. Cambridge University Press: pp: 441.

26. [APHA] American Public Health Association (1999) Standard methods for the examination of water and waste water, APHA-AWWA-WEF, New York, pp: 1325.

27. Yeshiemebet Major (2006) Temporal changes in the community structure and photosynthetic production of phytoplankton in Lake Babogaya, Ethiopia. MSc Thesis, School of Graduate Studies, Addis Ababa University, Addis Ababa, pp: 94.

28. Shumbulo E (2004) The temporal and spatial variations in the biomass and photosynthetic production of phytoplankton in relation to some physico-chemical variables in Lake Chamo Ethiopia. MSc. Thesis, Addis Ababa University, Addis Ababa, pp: 72.

29. Wood RB, Tailing JF (1988) Chemical and algal relationships in a salinity series of Ethiopian inland waters. Hydrobiologia 158: 29-67.
30. Shariff M (2014) Littoral and Limnetic Phytoplankton Distribution and Biodiversity in a Tropical Man-Made Lake, Malaysia. Advanced Studies in Biology 6(4): 149-168.

31. Happey-Wood C (1988) Ecology freshwater planktonic green algae. In C.D. SANDGREN, ed. Growth and reproductive strategies of freshwater phytoplankton. Cambridge: University Press, pp: 452.

32. Hoffman CE (1952) Limnological studies in Arkansas. II. The effect of intense rainfall on the abundance and vertical distribution of plankton in lake Fort Smith, Arkansas. Arkansas Acad Sci 5: 83-90.

33. Congressional Report HR (1970) Phosphates in Detergents and the Eutrophication of America's Waters. Committee on Government Operations 3: 911004.

34. Steinberg EW, Hartmann HM (1988) Planktonic bloom-forming cyanobacteria and the eutrophication in lakes. Environ Technol Lett 20(2): 279-287.

35. Cavalcanti Eah, Larrazábal Mel (2004) macrozooplâncton da zona econômica exclusiva do nordeste do brasil (segunda expedição oceanográficarevizee/ne ii) com ênfase em copepoda (crustacea). Revista Brasileira Zoologia 21(3): 467-475.

36. Yang B, Jiang YJ, He W, Liu WX, Kong XZ, et al. (2016) The tempo-spatial variations of phytoplankton diversities and their correlation with trophic state levels in a large eutrophic Chinese lake. Ecol Indic 66: 153-162.

37. Fayissa ZD, Kifle D (2014) The Study of Temporal Dynamics of Phytoplankton Biomass and Species Composition in Relation to Some Physical and Chemical Factors, Lake Kuriftu, Oromia Region, Ethiopia. (Burchell, 1822). Fish Aquac J 4(1): 084.

38. Gebre-Mariam Z (2002) The Ethiopian Rift Valley lakes: major threats and strategies for conservation. In: Tudorancea C \& Taylor WD (Eds.), Ethiopian Rift Valley Lakes. Biology of Inland Waters Series, Backhuys Publishers, Leiden, The Netherlands, pp. 259-271.

39. Durate P, Macedo MF, Da Fonseca LC (2006) The relationship between phytoplankton diversity and community function in a coastal lagoon. Hydrobiologia 183: 3 -18.

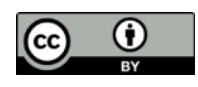

